\title{
Endothelium-derived microparticles from chronically thromboembolic pulmonary hypertensive patients facilitate endothelial angiogenesis
}

Daria Belik', Hilda Tsang ${ }^{1}$, John Wharton ${ }^{1}$, Luke Howard² ${ }^{2}$ Carmelo Bernabeu ${ }^{3}$ and Beata Wojciak-Stothard ${ }^{1 *}$ (D)

\begin{abstract}
Background: Increased circulating levels of endoglin ${ }^{+}$endothelial microparticles (EMPs) have been identified in several cardiovascular disorders, related to severity. Endoglin is an auxilary receptor for transforming growth factor $\beta$ (TGF- $\beta$ ) important in the regulation of vascular structure.

Results: We quantified the number of microparticles in plasma of six patients with chronic thromboembolic pulmonary hypertension (CTEPH) and age- and sex-matched pulmonary embolic (PE) and healthy controls and investigated the role of microparticle endoglin in the regulation of pulmonary endothelial function in vitro. Results show significantly increased levels of endoglin ${ }^{+}$EMPs in CTEPH plasma, compared to healthy and disease controls. Co-culture of human pulmonary endothelial cells with CTEPH microparticles increased intracellular levels of endoglin and enhanced TGF- $\beta$-induced angiogenesis and Smad1,5,8 phosphorylation in cells, without affecting BMPRII expression. In an in vitro model, we generated endothelium-derived MPs with enforced membrane localization of endoglin. Co-culture of these MPs with endothelial cells increased cellular endoglin content, improved cell survival and stimulated angiogenesis in a manner similar to the effects induced by overexpressed protein.

Conclusions: Increased generation of endoglin ${ }^{+}$EMPs in CTEPH is likely to represent a protective mechanism supporting endothelial cell survival and angiogenesis, set to counteract the effects of vascular occlusion and endothelial damage.
\end{abstract}

Keywords: Endoglin, Angiogenesis, Pulmonary hypertension, Microparticles

\section{Background}

Chronic thromboembolic pulmonary hypertension (CTEPH) is one of the leading causes of severe pulmonary hypertension (PH). In CTEPH, the formation of secondary nonresolving thromboemboli following the acute phase of thrombotic pulmonary embolism, leads to the obstruction of the pulmonary vascular bed followed by vascular remodelling and right heart hypertrophy $[1,2]$. Endothelial dysfunction and defective thrombus neovascularization

\footnotetext{
* Correspondence: b.wojciak-stothard@imperial.ac.uk

${ }^{1}$ Centre for Pharmacology and Therapeutics, Department of Medicine, Imperial College London, London, UK

Full list of author information is available at the end of the article
}

accompanied by a decrease in the expression of factors involved in proliferative pathways of vascular cells, such as bone morphogenetic protein receptor type 2 (BMPR2) or TGF- $\beta 1$, are thought to play a key role in the pathogenesis of CTEPH [3].

Circulating plasma microparticles (MPs) have been implicated in the pathogenesis of numerous cardiovascular disorders including pulmonary arterial hypertension $(\mathrm{PAH})$, but their cellular origin and associated specific roles have not been fully elucidated [4]. MPs are $<1 \mu \mathrm{m}$ membrane vesicles released after cell activation or apoptosis [5-7]. Depending on the size, formation and release mechanism, microparticles can be divided into 2 groups: exosomes and microvesicles. Exosomes (40-100 nm in diameter) derive from multivesicular bodies, which are 
compartments of the endosomal system, while microvesicles (100-1000 nm in diameter) derive from plasma membrane via shedding [8]. MPs harbor membrane proteins of the parent cells and contain intracellular signalling molecules such as microRNA or DNA fragments [7, 9].

Increased levels of endoglin ${ }^{+}\left(\mathrm{CD} 105^{+}\right)$endotheliumderived MPs (EMPs) can be detected in blood from remodelled pulmonary arterial hypertensive (PAH) lung $[10]$ and occluded coronary arteries $[11,12]$. Endoglin is an ancillary receptor for several TGF- $\beta$ superfamily ligands, including bone morphogenetic proteins (BMPs) [13]. Defective signaling of TGF- $\beta$ family of proteins is common to most forms of PH [14], including CTEPH [2]. Vascular injury, inflammation and hypoxia, in particular in combination with TGF- $\beta$ are strong inducers of endoglin expression [13]. Ectopic expression of endoglin promotes endothelial cell proliferation and inhibits hypoxia-induced endothelial cell apoptosis via TGF- $\beta$ / Alk-1 signaling $[15,16]$. Inhibition of endoglin signalling is associated with pulmonary vascular remodelling in pulmonary hypertension. Adult $\mathrm{Eng}^{+/-}$mice spontaneously develop signs of pulmonary hypertension that are attributable to uncoupled eNOS activity and reactive oxygen species (ROS) production causing progressive loss in pulmonary vascularity and increased muscularization of arterioles [17]. Interestingly, circulating levels of a soluble, truncated form of endoglin (Sol.Eng) are elevated in $\mathrm{PAH}$ and preeclampsia, hypercholesterolemia, atherosclerosis and acute myocardial infarction [17-19]. It has been postulated that Sol.Eng inhibits TGF- $\beta$ R2dependent signalling by binding circulating TGF- $\beta$ and attenuating vasorelaxation [20].

We hypothesized that CTEPH MPs can alter the function of healthy human pulmonary endothelial cells leading to changes that may affect disease progression. To address this hypothesis, we compared the effects of MPs isolated from plasma of CTEPH patients, pulmonary embolic patients and healthy individuals, on pulmonary endothelial survival, proliferation and angiogenesis in vitro. The effect of microparticle endoglin on endothelial function was studied with the use of microparticles from plasma and endothelial cells overexpressing recombinant endoglin.

\section{Methods}

\section{Blood collection and patient information}

Venous blood samples were obtained with local ethics committee approval and informed written consent from 6 CTEPH patients, 6 pulmonary embolic (PE) patients and 4 healthy individuals with no history of PE or PH (Table 1).

\section{Isolation and characterization of microparticle fraction from human plasma}

$25 \mathrm{~mL}$ of systemic venous blood was collected in the presence of $3.8 \%$ sodium citrate and subjected to
Table 1 Patient characteristics

\begin{tabular}{llll}
\hline & Healthy & CTEPH & PE \\
& $N=4$ & $N=6$ & $N=6$ \\
\hline Males/females & $2 / 2$ & $2 / 4$ & $2 / 4$ \\
Age, years & $54(42-60)$ & $68(52-81)$ & $68(45-91)$ \\
mPAP, mmHg & - & $42(30-57)$ & - \\
Warfarin/anticoagulants & - & 6 & 6 \\
Ca channel blockers & - & 1 & 1 \\
statins & - & 2 & 2 \\
paracetamol/aspirin & - & 3 & 4 \\
ET-1 antagonists & - & 5 & - \\
Diuretics & - & 4 & 1 \\
ACE inhibitors & - & 2 & 1 \\
Angiotensin II antagonists & - & - & 4 \\
$\beta$-blockers & & &
\end{tabular}

sequential centrifugation at $1,500 \mathrm{~g}$ for $15 \mathrm{~min}, 5,000 \mathrm{~g}$ for $5 \mathrm{~min}, 10,000 \mathrm{~g}$ for $30 \mathrm{~min}$ and 200,000 g for $60 \mathrm{~min}$. PKH26 Red Fluorescent Cell Linker Kit (Cat\# MINI26 and PKH26GL, Sigma, USA) was used to label the MPs according to the manufacturer's protocol. In order to prepare MPs for the flow cytometry analysis, the mixtures were diluted with filtered PBS (1:3) and $3 \mu \mathrm{m}$ latex polystyrene beads (Ref\# LB30-1ML, Sigma) were added. Phycoerythrin-conjugated anti-human VE-cadherin (CD144, cat. no c-1449-80, eBioscience, USA) was used to label endothelium- derived MPs. Human Annexin 5-FITC antibody (cat. no BMS306FI/20, eBioscience) was also used to label the phosphatidylserine-rich MPs.

\section{Scanning electron microscopy}

Human pulmonary artery endothelial cells (HPAECs) were plated on coverslips and incubated with purified MP fraction for $30 \mathrm{~min}$. The cells were then fixed in $4 \%$ formaldehyde in PBS for 15 min, washed with PBS and dehydrated by subsequent incubation in $20 \%, 50 \%$, $70 \%, 80 \%, 90 \%$ and $100 \%$ ethanol; 5 min in each solution. The cells were transferred into hexamethyldisilazane (HMDS) for $5 \mathrm{~min}$ and left to air dry. The samples were gold-coated for one minute at $20 \mathrm{~mA}$ and analysed with laser scanning microscope JEOL JSM-5610LV (JEOL, Japan) at $15 \mathrm{KV}$ in secondary imaging mode (SEI) and magnified images were taken with Helios 600 NanoLab (FEI Electron Microscopes, USA).

\section{Quantification of microparticles by flow cytometry}

Fluorescently labelled MPs were analysed with FACSCalibur flow cytometer (BD Biosciences, USA). MP concentration in plasma was calculated from the equation: 
$\underset{\mathrm{MP} / \mathrm{mL} \text { of plasma }}{\text { Estimated }}=\frac{(203111) /(\text { no. of beads counted }) *(\text { no. of MP counted }) * \mathrm{x}}{\text { Volume of plasma used }(\mathrm{mL})}$

$3 \mu \mathrm{m}$ polystyrene beads were used to estimate the concentration of MPs per mL of plasma. 203111 is a constant, provided by the manufacturer. The number of beads counted is the number of events identified as beads due to their size and characteristic density plot. Number of MP counted is the number of events detected as MPs due to positive staining. $\mathrm{X}$ is the dilution factor.

\section{Quantification of microparticles by laser light scattering spectroscopy}

$0.3 \mathrm{~mL}$ of the MP suspensions were analysed with the Nanosight LM10-HSGFT14 Nanoparticle Analysis System (Nanosight, UK), using Nanoparticle Tracking Analysis (NTA) software (Nanosight).

\section{Quantification of endoglin in microparticle fractions} Endoglin was quantified in MP fractions using Human Endoglin/CD105 Quantikine ELISA Kit (R\&D), according to the manufacturer's protocol.

\section{Cell culture}

HPAECs (PromoCell GmbH, Germany) were cultured in endothelial cell growth medium 2 (ECGM2) (PromoCell $\mathrm{GmbH}$, Germany) containing $2 \%$ foetal calf serum, growth factor supplement mix and penicillin/streptomycin in tissue culture dishes coated with $10 \mu \mathrm{g} / \mathrm{mL}$ bovine fibronectin (Sigma) in a humidified incubator $(5 \%$ $\left.\mathrm{CO}_{2}\right)$ at $37^{\circ} \mathrm{C}$.

\section{Endoglin expression vectors}

The pDisplay-HA-L-endoglin expression vector containing the HA-tagged human full length $(\mathrm{L})$-endoglin has been described in [21]. pDisplay ${ }^{\mathrm{mi}}$ (Invitrogen, USA) is a $5.3 \mathrm{~kb}$ mammalian expression vector that allows display of proteins on the cell surface. Proteins expressed from pDisplay $^{\text {ma }}$ are fused at the N-terminus to the murine Ig $\mathrm{K}$-chain leader sequence, which directs the protein to the secretory pathway. The pCEXV-HA-L-endoglin expression vector contains the HA-tagged full length human L-endoglin, including its leader sequence and will be described elsewhere. Empty pCEEXV vector and empty pDisplay vector were used as transfection controls. HPAECs were transfected using Amaxa ${ }^{\mathrm{Tm}}$ Basic Nucleofector $^{\text {Ta }}$ Kit for Primary Mammalian Endothelial Cells (Lonza, Switzerland) applying optimal Nucleofector ${ }^{\mathrm{Tx}}$ program M-003. The cells were used for experiments $18 \mathrm{~h}$ post-transfection.

\section{In vitro model of MP generation}

MPs were generated by an established method of serum starvation [22]. The untransfected or transfected HPAECs were grown in T75 flasks in $10 \mathrm{~mL}$ of serumand growth factor-depleted medium. Following $24 \mathrm{~h}$ incubation, MPs were isolated from HPAEC conditioned media by sequential centrifugation.

\section{HPAEC-MP co-culture experiments}

In experiments involving co-culture of HPAECs with MPs, MPs obtained from $2 \mathrm{~mL}$ plasma were resuspended in $2 \mathrm{~mL}$ of culture medium and plated on cells. Endoglin ${ }^{-}$or VE-cadherin ${ }^{-} \mathrm{MP}$ fractions were obtained by antibody-mediated immunoprecipitation with Dynabeads (Life Technologies). Briefly, $2 \mathrm{~mL}$ of MP suspension was incubated o/n with $30 \mu \mathrm{L}$ Dynabeads linked with $5 \mu \mathrm{g}$ of mouse anti-human endoglin (Millipore, USA) or mouse monoclonal anti-VE-cadherin antibody (Santa Cruz Biotechnology). The suspension was then placed in a magnetic holder and the supernatant was carefully collected without disturbing Dynabeads attached to the side of the tube. The beads were washed $3 \mathrm{x}$ in PBS. All samples (the beads, full MP fraction, VEcadherin $^{-}$and endoglin ${ }^{-}$MPs) were resolved by SDSPAGE (30 $\mu \mathrm{g}$ protein/lane) and studied by western blotting. Endoglin levels were also measured in ELISA assay, as described above.

In co-culture experiments, HPAECs grown in 96-well plates were incubated with MP suspension obtained from patient plasma or from endoglin-overexpressing HPAECs. In some experiments, TGF- $\beta(10 \mathrm{ng} / \mathrm{mL})$ was added to the cells $1 \mathrm{~h}$ after the addition of MPs and incubated for further $1 \mathrm{~h}$ (smad phosphorylation) or $18 \mathrm{~h}$ (cell proliferation, angiogenesis and BMPRII expression).

\section{Immunostaining and confocal laser scanning microscope} HPAECs grown on plastic coverslips in 24-well plates were incubated with MPs for $1-18 \mathrm{~h}$, as appropriate. The cells were then fixed in $4 \%$ formaldehyde in PBS, permeabilised with $0.1 \%$ Triton X-100 and incubated with $2 \%$ bovine serum albumin (BSA) to block nonspecific antibody binding [23]. The coverslips were incubated with $50 \mu \mathrm{L}$ of mouse anti-endoglin monoclonal antibody (10 $\mu \mathrm{g} / \mathrm{mL}$, Millipore, USA) and rabbit anti-HA 
polyclonal antibody $(5 \mu \mathrm{g} / \mathrm{mL}$, Santa Cruz Biotechnology, USA) in PBS for $1 \mathrm{~h}$. Coverslips were then washed in PBS and incubated with TRITC (Tetramethylrhodamine-5-(and 6)-isothiocyanate)-phalloidin (1:100, Sigma) and Cy5-conjugated goat anti-mouse and FITC (Fluorescein isothiocyanate)-conjugated goat anti-rabbit antibody (10 $\mu \mathrm{g} / \mathrm{mL}$, Invitrogen, USA) for $1 \mathrm{~h}$, washed in PBS and mounted in Vectashield mountant with nuclear stain DAPI (Vector Laboratories, USA). Fluorescent confocal images were taken using Leica TCS SP5 (Leica Microsystems, Germany).

\section{Western blotting}

Following electrophoresis and protein transfer, PVDF membranes were incubated overnight with mouse monoclonal anti-endoglin antibody $(1 \mu \mathrm{g} / \mathrm{mL}, \mathrm{R} \& \mathrm{D}$, USA), mouse monoclonal anti-HA-probe antibody (1 $\mu \mathrm{g} / \mathrm{mL}$, Santa Cruz Biotechnology, USA), mouse monoclonal anti-VE-cadherin antibody $(1 \mu \mathrm{g} / \mathrm{mL}$, Santa Cruz Biotechnology, USA), mouse monoclonal antiBMPRII antibody $(0.5 \mu \mathrm{g} / \mathrm{mL}, \mathrm{R} \& \mathrm{D})$, mouse monoclonal anti- $\beta$-actin antibody $(0.2 \mu \mathrm{g} / \mathrm{mL}$, Sigma $)$, rabbit anti-psmad1,5,8 $(0.5 \mu \mathrm{g} / \mathrm{mL}$; Santa Cruz Biotechnology, USA) or mouse monoclonal anti-smad 1 antibody $(0.5 \mu \mathrm{g} / \mathrm{mL}$; Santa Cruz Biotechnology, USA). The membranes were washed in Tris-buffered saline with Tween 20, incubated with goat anti-mouse- or goat anti-rabbit polyclonal HRP-conjugated antibodies $(0.2 \mu \mathrm{g} / \mathrm{mL}$; DAKO, USA) for $1 \mathrm{~h}$. Blots were developed in Luminata Crescendo Western HRP substrate (Millipore, USA) and analysed in BioRad ChemiDoc Imager.

\section{Angiogenesis assay}

Untransfected or transfected HPAECs were seeded on $40 \mu \mathrm{L}$ of growth factor-reduced Matrigel (Corning ${ }^{\mathrm{Tw}}$, \# $354230)$ in a 96-well plate $\left(14 \times 10^{3}\right.$ cells per well $)$ in growth factor-free medium containing $0.5 \% \mathrm{FBS}$, with or without MPs (full fraction, VE-cadherin ${ }^{-}$or endoglin ${ }^{-}$) or TGF- $\beta$ (10 ng/mL), as appropriate. Following $18 \mathrm{~h}$ incubation, the cells were fixed in $4 \%$ formaldehyde in PBS and photographed under a phase contrast microscope (Olympus IX70, Japan) equipped with a Peltier CCD camera. Total tube length was calculated using Image J software.

\section{Proliferation assay (MTS)}

HPAECs $\left(7 \times 10^{3}\right.$ cells per well) were cultured in 96 -well plates in growth factor-free medium containing $0.5 \%$ FBS, with or without MPs and TGF- $\beta(10 \mathrm{ng} / \mathrm{mL})$, as appropriate. Following $18 \mathrm{~h}$ incubation, cell proliferation was measured using CellTiter $96^{\circ}$ Aqueous One Solution Cell Proliferation Assay System (Promega, USA). In this assay, the conversion of MTS tetrazolium compound into a coloured formazan product is accomplished by
$\mathrm{NADPH}$ or $\mathrm{NADH}$ generated by dehydrogenase enzymes in metabolically active cells. The quantity of the coloured formazan product determined by absorbance at $490 \mathrm{~nm}$ is directly proportional to the number of living cells and commonly associated with cell proliferation and migration [24].

\section{Apoptosis assay}

Untransfected or transfected HPAECs were cultured overnight in 96-well optical bottom plates at cell density of $7 \times 10^{3}$ cells per well in growth factor-free medium containing $0.1 \%$ foetal calf serum, with or without MPs, as appropriate. $100 \mu \mathrm{L}$ of $\mathrm{DiOC7}(3)$ (3,3'-Diheptyloxacarbocyanine Iodide), a cell-permanent, green fluorescent, lipophilic dye that selectively labels the mitochondria in live cells (1: 1000 dilution in PBS, Life Technologies, Invitrogen, USA) was added into each well. After $45 \mathrm{~min}$ incubation at $37{ }^{\circ} \mathrm{C}$, fluorescence was read at excitation/emission 490/525 nm in GloMaxMulti + Microplate Multimode Reader (Promega, USA).

\section{Human angiogenesis microarray}

The levels of pro-angiogenic cytokines in CTEPH EMP fraction were studied with Proteome Profiler $^{\mathrm{rm}}$ Human Angiogenesis Array (R\&D Systems ${ }^{\mathrm{Tn}}$, \# ARY007), according to the manufacturer's protocol. Briefly, EMPs were removed from $5 \times 10^{6} \mathrm{CTEPH}$ MPs fraction by Dynabeads antibody capture, as described above. Following 3 washes in PBS, Dynabeads with the bound EMPs were resuspended in $1 \mathrm{ml}$ of PBS and incubated overnight with the human angiogenesis microarray membrane. More information about the assay can be found on https://resour ces.rndsystems.com/pdfs/datasheets/ary007.pdf.

\section{Ethics, consent and permissions}

All procedures performed in studies involving human participants were in accordance with the ethical standards of the institutional and/or national research committee and with the 1964 Helsinki declaration and its later amendments or comparable ethical standards.

Informed consent was obtained from all individual participants included in the study.

\section{Statistical analysis}

All experiments were performed in triplicate or, as indicated. Data was analysed using one-way ANOVA (GraphPad Prism Version 6) followed by Tukey's post-test.

\section{Results}

CTEPH patients show increased levels of endoglin ${ }^{+}$ endothelium-derived microparticles, compared with healthy and disease controls

Electron scanning microscopy analysis confirmed vesicular appearance and sizes ranging from 0.01 to $1.5 \mu \mathrm{m}$ of 
MPs purified from patient plasma (Fig. 1a). Flow cytometry analysis revealed significantly higher number of annexin $\mathrm{V}^{+}$PKH $26^{+}$MPs in CTEPH plasma compared to pulmonary embolic patients and healthy controls $\left(2.5 \times 10^{6} \mathrm{MPs} / \mathrm{mL}\right.$ compared to $1.4 \times 10^{6} \mathrm{MPs} / \mathrm{mL}$ and $1.1 \times 10^{6} \mathrm{MPs} / \mathrm{mL}$ respectively) (Fig. $1 \mathrm{~b}$ ). The number of endothelial (VE-cadherin ${ }^{+}$) MPs (EMPs) in CTEPH plasma was $7.5 \times 10^{4} \mathrm{EMPs} / \mathrm{ml}(\sim 3 \%$ of total MP fraction), which was $\sim 2-2.8$-fold higher than the number of EMPs found in control groups (Fig. 1c). MP fraction from CTEPH patients also contained 2.5-fold higher levels of endoglin, compared with healthy and PE controls (Fig. 1d). While the levels of endoglin in CTEPH microparticle fraction were elevated, there were no significant differences in the total plasma levels of endoglin between the studied groups $(4.1 \pm 0.5 \mathrm{ng} / \mathrm{mL}$ in healthy plasma, $3.9 \pm 0.4 \mathrm{ng} / \mathrm{mL}$ for CTEPH and $3.2 \pm 0.5 \mathrm{ng} / \mathrm{mL}$ for PE).

CTEPH MPs stimulate endothelial angiogenesis in vitro We further sought to establish the effect of MPs on human pulmonary endothelial function in vitro. MPs were added to HPAEC cultures at the concentration found in plasma and incubated for 1-18 h. Confocal microscopy analysis confirmed that microparticles were internalised by the cells within the first hour of incubation (data not shown).

Co-culture of HPAECs with CTEPH microparticles increased endothelial angiogenesis (tube formation) by $\sim 2.5$ fold $(P<0.001$, comparison with healthy and disease controls) and the effect was dose-dependent (Additional file 1: Figure S1).
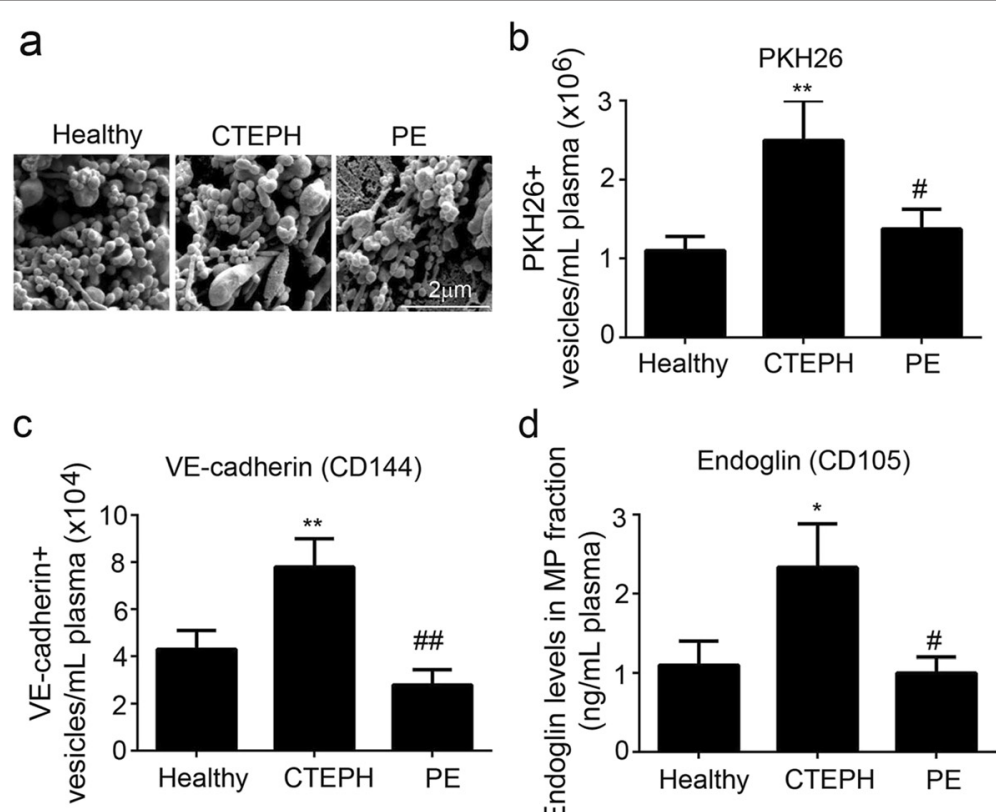

d

e
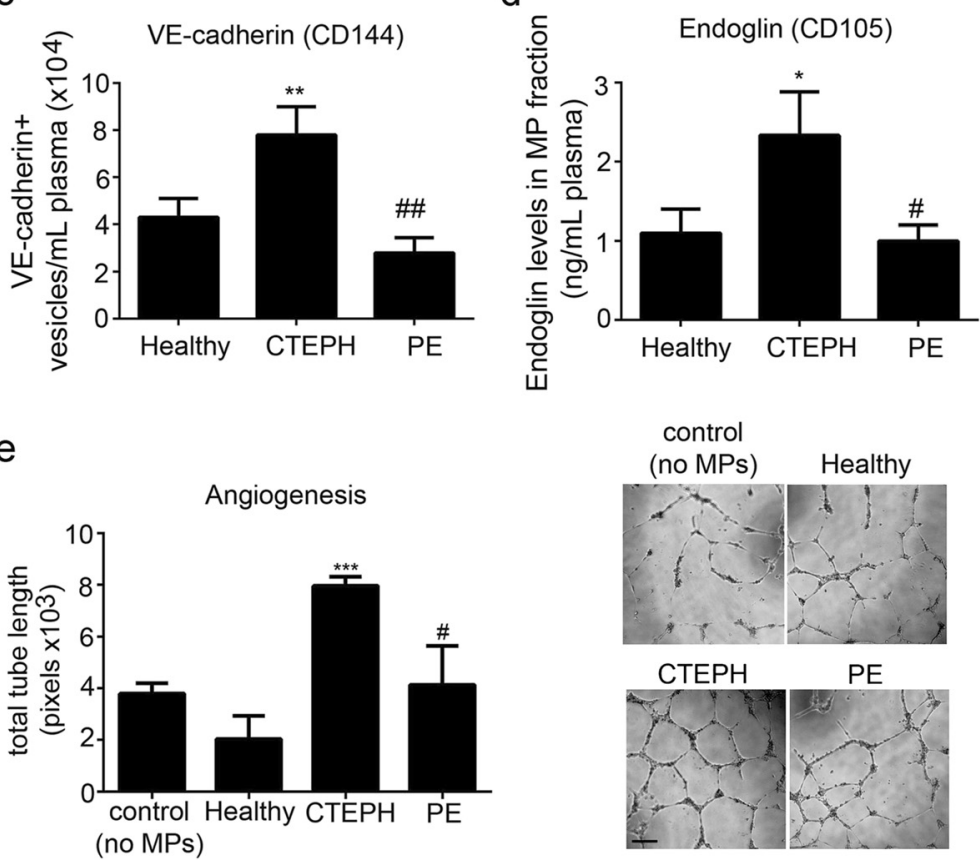

Fig. 1 CTEPH plasma shows increased levels of endothelium-derived microparticles compared with pulmonary embolic and healthy controls. a Scanning electron microscope images of MP fractions.from a healthy volunteer, $C T E P H$ and PE patients. Bar $=2 \mu \mathrm{m}$. $\mathbf{b}$ Number of membrane $\left(\mathrm{PKH}_{2} 6^{+}\right) \mathrm{MPs}$ and $\mathbf{c}$ number of VE-cadherin ${ }^{+}\left(\mathrm{CD} 144^{+}\right)$MPs in plasma of healthy voulnteers, CTEPH and PE patients, as indicated; $\mathbf{d}$ Endoglin levels in MP fractions; ELISA assay; e endothelial angiogenesis (Matrigel tube formation) in HPAECs cultured with MPs isolated from CTEPH, PE or healthy plasma, as indicated. ${ }^{*} P<0.01 ;{ }^{*} P<0.05$, comparisons with healthy controls, ${ }^{\# \#} P<0.01 ;{ }^{\#} P<0.05$, comparisons with $C T E P H ; N=4-6$. Representative images of tube formation are shown beside the graph. Bar $=50 \mu \mathrm{m}$ 
Endoglin ${ }^{+}$endothelium-derived MPs (EMPs) from CTEPH blood enhance TGF- $\beta$-induced angiogenesis and Smad1,5,8 phosphorylation in HPAECs

CTEPH MPs stimulated proliferation and tube formation in the untreated and TGF- $\beta$-treated HPAECs (10 $\mathrm{ng} / \mathrm{mLTGF}-\beta, 18 \mathrm{~h}$ incubation). The stimulatory responses were attenuated by removing endoglin ${ }^{+}$and VE cadherin $^{+}$MPs from the total MP fraction (Fig. 2a, b and Additional file 1: Figure S2). CTEPH MPs significantly increased TGF- $\beta$-induced Smad1/5/8 phosphorylation in
HPAECs, likely to indicate enhanced endoglin signalling (Fig. 2c, d). This response was prevented by removing endoglin $^{+}$VE-cadherin ${ }^{+}$MPs from the total MP fraction (Fig. 2d).

\section{Microparticle-mediated transfer of membrane endoglin facilitates the pro-angiogenic and anti-apoptotic effects of MPs}

Incubation of HPAECs with the full (unmodified) MP fraction from CTEPH plasma increased endoglin
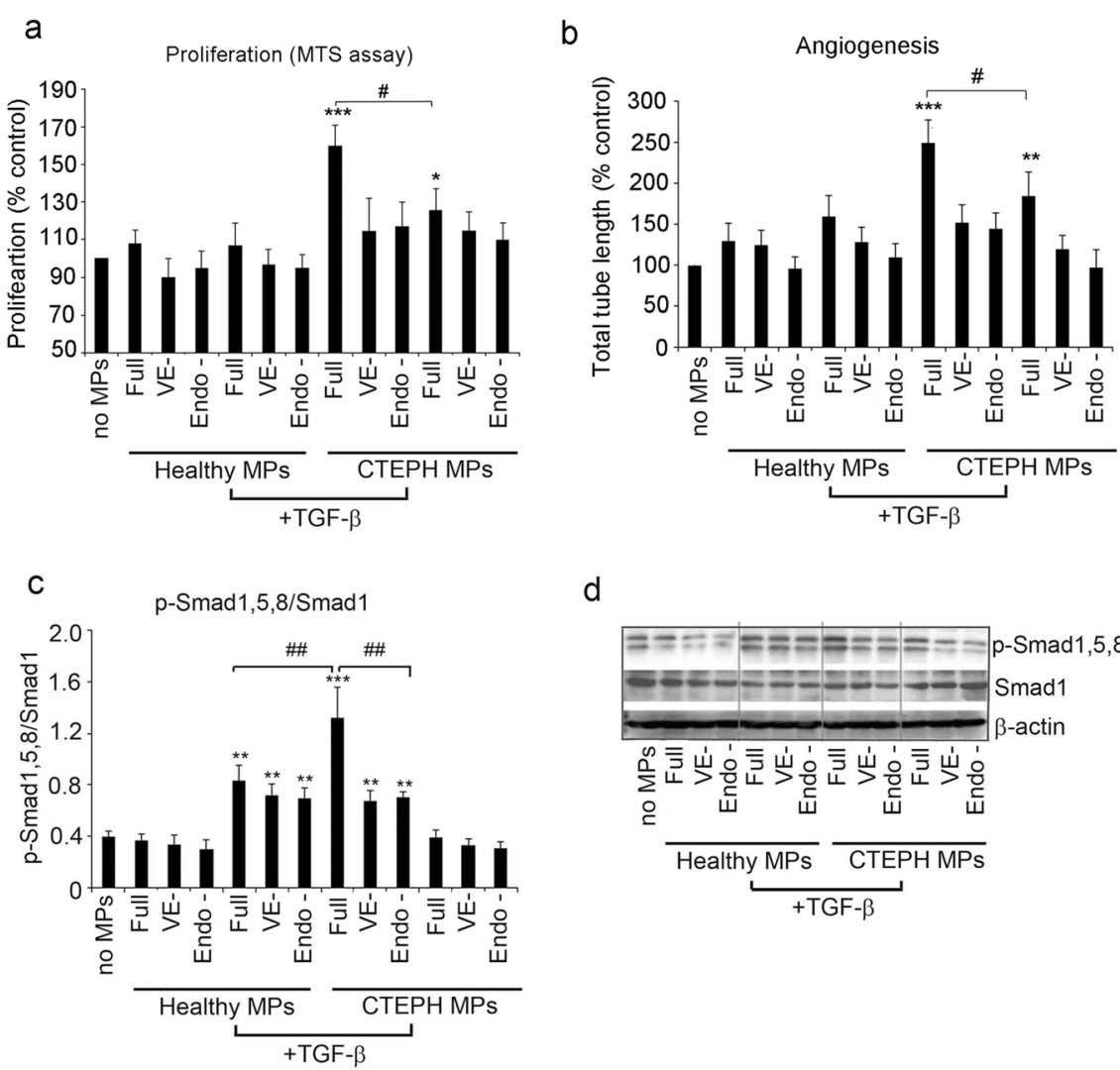

d
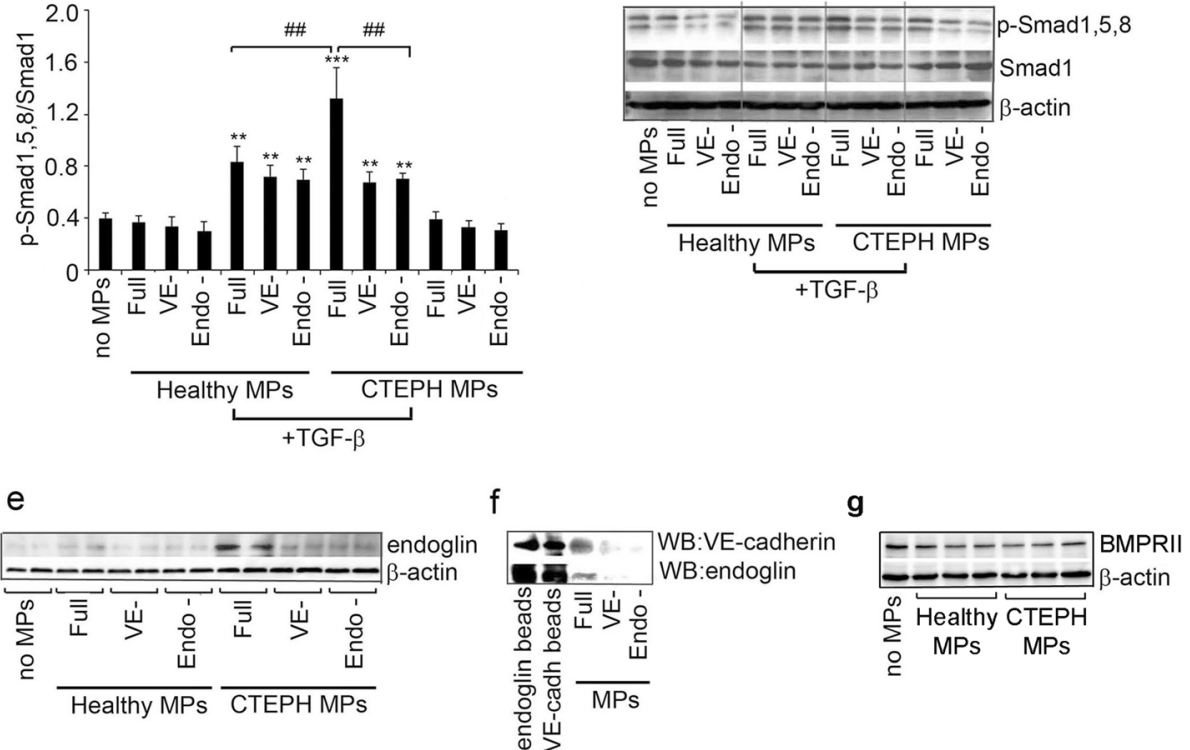

Fig. 2 Endoglin ${ }^{+}$EMPs increase cell proliferation, angiogenesis and TGF- $\beta$ signalling in HPAECs. a Proliferation and (b) angiogenesis in HPAECS incubated with unmodified (full), VE cadherin- depleted $\left(V^{-}\right)$or endoglin- depleted (endoglin ${ }^{-}$) MP fractions, in the absence or in the presence of TGF- $\beta$ (10 ng/mL; $18 \mathrm{~h}$ ), as indicated. Graph in (c) and a corresponding, representative western blot in (d) show phosphorylation changes of smad $1 / 5 / 8$ in cells pre-incubated with MPs for $1 \mathrm{~h}$ and then treated with $10 \mathrm{ng} / \mathrm{mL}$ TGF- $\beta$ for $1 \mathrm{~h} .{ }^{*} P<0.05 ;{ }^{* *} P<0.01$; ${ }^{* * *} P<0.001$, comparisons with healthy controls; ${ }^{\# P} P<0.05,{ }^{\# \#} P<0.01$ comparisons, as indicated. $N=3$. e Changes in endoglin expression in HPAECs cultured for $18 \mathrm{~h}$ with unmodified (full), VE $\mathrm{E}^{-}$and endoglin ${ }^{-}$MPs from healthy volunteers or CTEPH patients. $\mathbf{f}$ BMPRIl expression in HPAECs incubated with MPs for $18 \mathrm{~h}$. g Western blot showing VE-cadherin (CD144) and endoglin (CD105) levels in MP fractions, as indicated. Briefly, plasma MPs were incubated o/n with Dynabeads coupled with antibodies against CD144 or CD105. The beads with captured proteins were collected and washed in PBS. Then the beads and, full MP fraction and endoglinNE-cadherin-depleted fractions were resolved by electrophoresis. Changes in endoglin and VE-cadherin levels were studied by western blotting 
expression in HPAECs, while endoglin- and VEcadherin-depleted fractions had no significant effect (Fig. 2e). Depleting microparticles of VE-cadherin removed endoglin and vice versa, depleting microparticles of endoglin removed VE-cadherin from MP fraction (Fig. $2 \mathrm{f}$ and Additional file 1: Figure S3), indicating that the endothelium-derived (VE-cadherin ${ }^{+}$) MPs were the main carriers of endoglin. Preliminary microarray analysis of CTEPH EMP fraction $(n=2)$ showed the presence of plasminogen activator inhibitor 1 (Serpine1) and traces of urokinase plasminogen activator (uPA) but did not detect measurable levels of any other pro-angiogenic factors included in the assay (Additional file 1: Figure S4).

To verify whether the membrane-bound endoglin plays a role in MP-induced responses, we overexpressed L-endoglin in HPAECs using the mammalian expression vector pDisplay that allows display of this protein on the cell surface [21]. pDisplay-HA-L-endoglin vector contains the HA-tagged full length human L-endoglin with the leader sequence of Igk-chain. To investigate potential role of the membrane localization of L-endoglin, we also used another expression vector, pCEXV-HA-Lendoglin that encodes the own leader sequence of endoglin. Empty vectors were used as transfection controls.

Recombinant endoglin localised in F-actin-rich membrane protrusions along the leading edge of migrating endothelial cells (Fig. 3a), similar to the localization observed in human prostate cancer cells [25]. Transfection of cells with pDisplay-HA-L-endoglin and pCEXV-HAL-endoglin ( $\sim 70 \%$ transfection efficiency) increased endoglin levels by $\sim 2$-fold (Fig. 3b). Overexpression of pDisplay-HA-L-endoglin or pCEXV-HA-L-endoglin did not affect cell proliferation but stimulated tube formation and inhibited starvation-induced apoptosis in HPAECs (Fig. 3c-f), with pDisplay-HA-L-endoglin having a more pronounced effect.

We further aimed to explore whether endoglin effects can be passed onto cultured cells by MPs generated from endoglin-overexpressing HPAECs. To generate MPs, L-endoglin overexpressing HPAECs were starved for $24 \mathrm{~h}$ in serum- and growth factor-free media. The cells produced an average of $0.2-0.32 \times 10^{6} \mathrm{MPs} / \mathrm{mL}$ of medium. These microparticles were then incubated with HPAECs in a similar manner to plasma-derived MPs. Confocal microscopy analysis documented a transfer of HA-endoglin-bearing MPs to the recipient cells (Fig. 4a). Incubation of HPAECs with microparticles generated by pDisplay-HA-L-endoglin-overexpressing cells inhibited starvation-induced apoptosis and significantly increased endothelial tube formation in HPAECs, while control MPs (generated by HPAECs transfected with an empty pDisplay vector) did not have a significant effect (Fig. 4b-e).

\section{Discussion}

We are first to demonstrate that CTEPH patients show increased levels of circulating endoglin ${ }^{+}$EMPs compared with healthy and pulmonary embolic control groups. Moreover, we show that these microparticles can evoke pro-survival and pro-angiogenic responses in primary human pulmonary endothelial cells.

MP-mediated transfer of membrane-associated receptors has been documented in a variety of cell types [26]. MPs may fully or partially fuse with the target cell, allowing for a complete or selective transfer of contents including membrane and cytosolic proteins, bioactive lipids, or even whole cell organelles [26-28]. The mechanism, depending on MP origin and cell type, is thought to involve integrin $\alpha 4$ or annexin $\mathrm{V} /$ phosphatidylserine signalling [26]. The role of microparticles in disease may be beneficial or detrimental, depending on the cellular source. For instance, MPs from animals with hypoxiainduced $\mathrm{PH}$ inhibit endothelium-dependent vasoreactivity of isolated pulmonary arteries and decrease nitric oxide production in isolated pulmonary endothelial cells [29]. On the other hand platelet or T-cell-derived MPs are thought to have a pro-proliferative and proangiogenic effects [30]. Our results support the notion that MPs secreted by endothelial cells in conditions of metabolic stress promote endothelial repair and counteract endothelial damage [31].

Pro-proliferative and pro-angiogenic effects of CTEPH EMPs were particularly evident in the presence of exogenous TGF- $\beta$. This may be explained, at least in part, by endoglin-mediated increase in TGF- $\beta$-induced smad1,5,8 phosphorylation. TGF- $\beta$ regulates cell proliferation, differentiation, migration, synthesis of the extracellular matrix $[32,33]$ and promotes endothelial cell survival by activating ALK1/Smad 1/5/8 signalling [15, 34]. Interestingly, a weak stimulatory effect was also observed in the absence of exogenous TGF- $\beta$, likely to result from the effects induced by other components of EMPs. For instance, EMPs generated by apoptotic endothelial cells contain miR-126, known to promote endothelial angiogenesis [35, 36]. In addition, CTEPH EMP fraction contained plasminogen activator inhibitor 1 (Serpin E1) and traces of urokinase plasminogen activator (uPA). Serpine 1 is a serine protease inhibitor that stabilizes capillary vessel structure, regulates cell invasive behaviour and enhances TGF- $\beta$ signaling [37, 38].

Reparative actions of CTEPH MPs may be attributed to endothelial endoglin ${ }^{+}$MP fraction but the precise mechanism will require further studies. Confocal microscopy analysis documented the presence of microparticle-derived HA-tagged L-endoglin in recipient endothelial cells, suggesting a possibility of a functional receptor transfer. Recycling of membrane receptors carried by microparticles has been shown in 

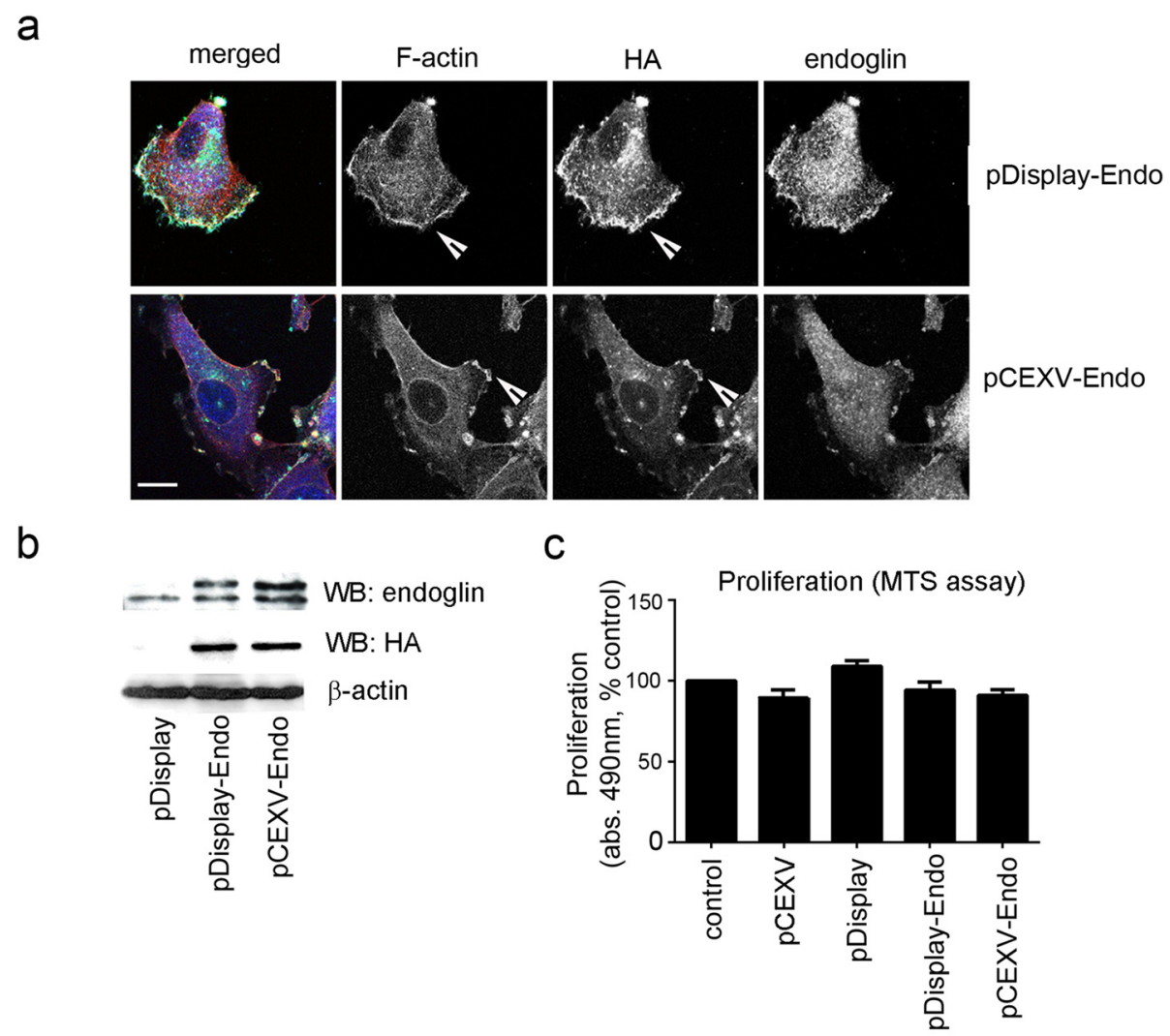

d

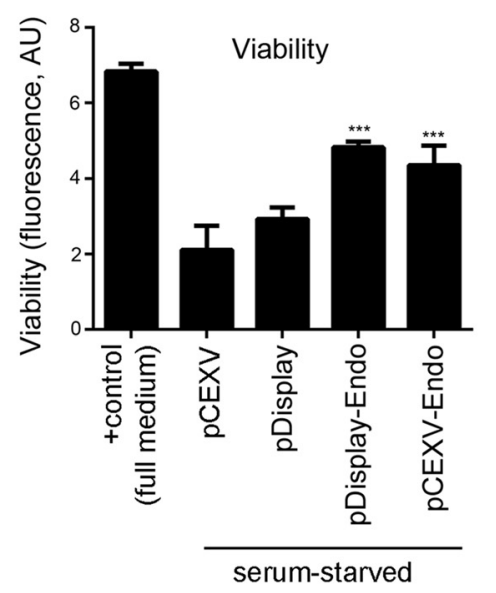

e

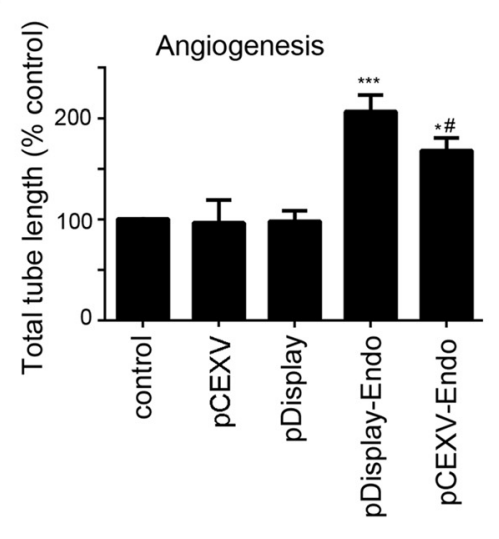

f

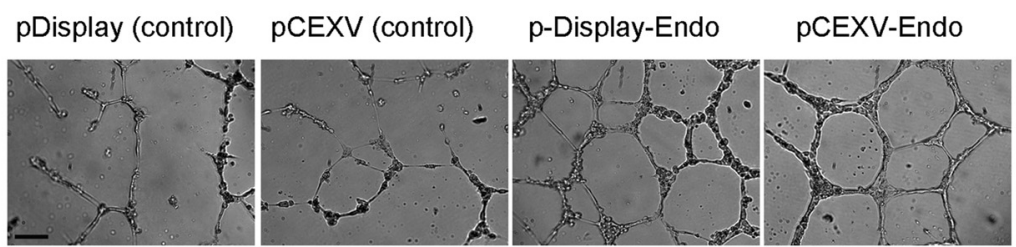

Fig. 3 (See legend on next page.) 
(See figure on previous page.)

Fig. 3 L-endoglin induces pro-survival and pro-angiogenic responses in HPAECs. a Cellular localization of endoglin and F-actin in HPAECs transfected with pDisplay-HA-L-endoglin and PCEXV-HA-L-endoglin following an overnight incubation. The arrows in (a) point to the lamellipodia where recombinant endoglin co-localises with F-actin. In the merged image, F-actin is red, endoglin is green and HA-tag is blue. Bar $=10 \mu \mathrm{m}$. $\mathbf{b}$ Corresponding western blot shows expression levels of HA-tagged endoglin, total endoglin and $\beta$-actin in HPAECs transfected with empty pDisplay, pDisplay-HA-L-endoglin and PCEXV-HA-L-endoglin, as indicated. c Cell proliferation; (d) cell viability and (e) angiogenesis (tube formation) in HPAECs overexpressing pDisplay-HA-L-endoglin and pCEXV-HA-L-endoglin or transfected with control empty vectors, as indicated. In (d) cells were serum-starved ( $0.1 \%$ serum; $18 \mathrm{~h}$ ), while the non-starved (incubated with full culture media) cells served as a positive (+) control. In (e) HPAECs were cultured in growth factor-depleted and serum-reduced ( $0.5 \%$ serum) media. ${ }^{*} P<0.05$; ${ }^{* *} P<0.001$, comparisons with vector controls; $\# P<0.05$, comparison with pDisplay-L-endoglin. $N=4$. $\mathbf{f}$ Representative images of tube formation in cells treated, as indicated. Bar $=50 \mu \mathrm{m}$

various cell types [39-44]. Future studies will need to determine whether the recombinant endoglin was indeed recycled to the surface and remained functional. Of interest, platelet-derived MPs can increase surface expression of chemokine receptor CXCR4 by modification of receptor transfer, internalisation and externalisation as well as modified gene regulation $[26,45]$. The type of endoglin microparticle carrier will also need further investigation. While microvesicles budding off the plasma membrane are most likely to play a role, exosomes can also carry surface proteins of their mother cells: exosomes from antigen presenting cells harbor MHCII on their surface, exosomes from reticulocytes contain the transferrin receptor, and exosomes from T-cells carry the TCR/CD3/zeta complex [46-48]. It is conceivable that local accumulation of endoglin ${ }^{+}$ microparticles in distal vasculature may promote angiogenesis and counteract the effects of Sol.Eng or other

\section{a}

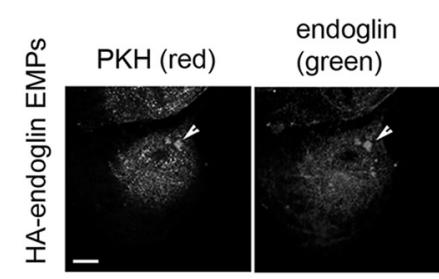

HA-tag co-localization $\begin{array}{ll}\text { HA-tag } & \text { (white pixels) }\end{array}$
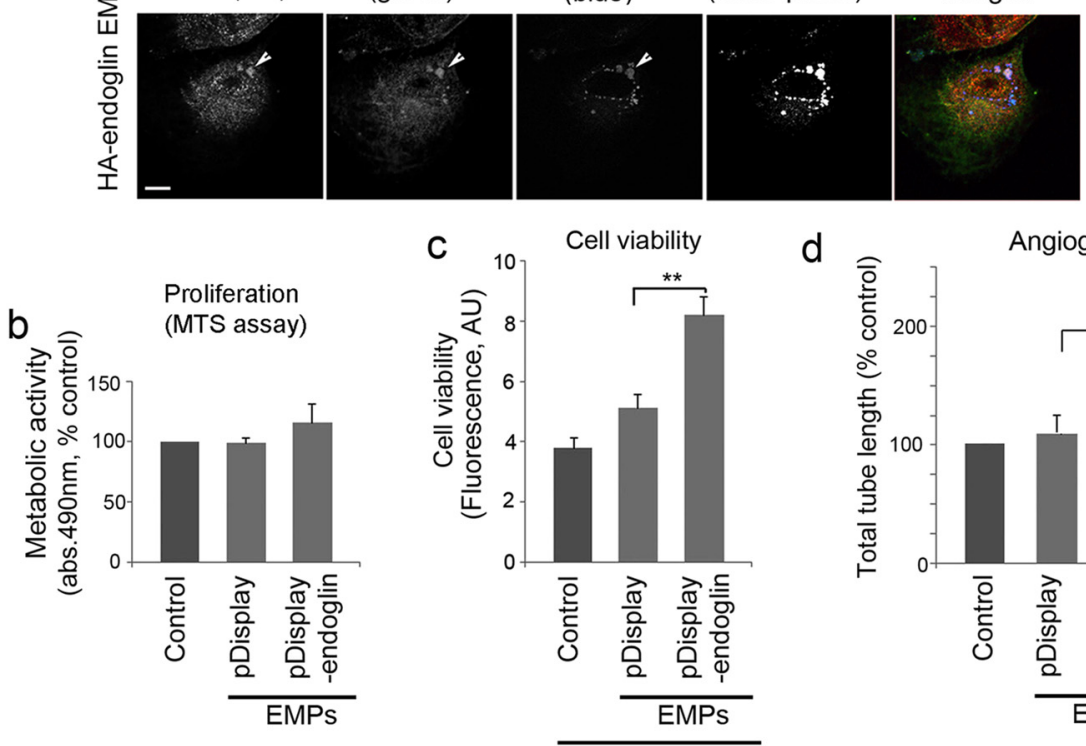

d

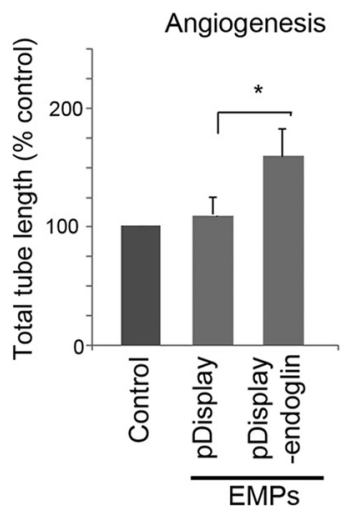

e

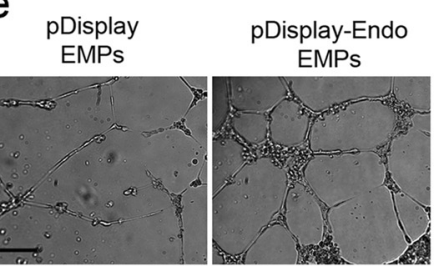

Fig. 4 MPs obtained from endoglin-overexpressing HPAECs stimulate endothelial cell survival and angiogenesis in vitro. a Internalisation of fluorescently-labelled MPs by HPAECs (2 h incubation). In the merged image, PKH26 is red, HA is blue and endoglin is green, as indicated. White pixels mark co-localization of PKH26, HA and endoglin and indicate intracellular localization of microparticles carrying recombinant endoglin (Image J analysis). Bar $=2 \mu \mathrm{m}$. b Cell proliferation, (c) cell viability and (d) angiogenesis/tube formation in HPAECs treated with MPs isolated from untreated (control) HPAECs, cells transfected with empty pDisplay vector and HPAECs overexpressing pDisplay-L- endoglin, as indicated. e Representative images of tube formation in cells transfected with pDisplay or pDisplay-L-endoglin. ${ }^{*} P<0.05$; ${ }^{* *} P<0.001$, comparison with transfection controls; Bar $=50 \mu$ m; $n=3$ 
factors inducing endothelial senescence. Microparticlemediated endoglin delivery may also have potential therapeutic implications in angiogenic disorders associated with abnormal endoglin function, such as hereditary hemorrhagic telangiectasia [49].

\section{Conclusions}

Our study shows that CTEPH blood contains increased levels of endoglin ${ }^{+}$endothelial microparticles and that these microparticles induce pro-survival and proangiogenic responses in human pulmonary endothelial cells, likely to reflect a healing mechanism set to counteract the effects of vascular occlusion and endothelial damage.

\section{Additional file}

Additional file 1: Figure S1. Endothelial tube formation induced by CTEPH microparticles. HPAECs were cultured on Matrigel in serum-reduced ( $0.5 \%$ serum) medium with different numbers of CTEPH microparticles, as indicated. Tube formation was scored after $18 \mathrm{~h}$ of incubation. ${ }^{*} P<0.01$, comparison with untreated controls. Figure S2. Tube formation in HPAECS incubated with TGF- $\beta$ and MPs. Representative images of tube formation in HPAECs incubated with MP fractions (full and endog $\operatorname{lin}^{-}$) from healthy and CTEPH plasma, with or without TGF- $\beta$ ( $10 \mathrm{ng} / \mathrm{mL} ; 18 \mathrm{~h}$ ). Bar $=50 \mu \mathrm{m}$. Figure S3. Endoglin levels in full MP fractions (containing endoglin ${ }^{+}$MPs) and endoglin-depleted (endoglin ${ }^{-}$) MP fractions. Endog in $^{+}$MPs were removed by Dynabeads-mediated immunoprecipitation and endoglin levels were measured with Human Endoglin/CD105 Quantikine ELISA Kit.**P $<0.001$, Student $t$-test, $n=6$. Figure S4. Pro-angiogenic factors in CTEPH EMP fraction. (a) Proteome Profiler ${ }^{\mathrm{TM}}$ Human Angiogenesis Array membrane was incubated with CTEPH EMPs (image representative of $n=2$ ). (R) shows reference spots, (1) corresponds to Serpin E1 and (2) corresponds to uPA, as indicated. Full information about the microarray layout can be found on https://resources.rndsystems.com/pdfs/datasheets/ary007.pdf. A schematic diagram of microarray is shown in (b). (DOCX $479 \mathrm{~kb}$ )

\section{Abbreviations}

EMP: endothelial microparticles; CTEPH: chronic thromboembolic pulmonary hypertension; PE: pulmonary embolism; TGF- $\beta$ : transforming growth factor $\beta$; FITC: Fluorescein isothiocyanate; VE-cadherin: vascular endothelial cadherin.

\section{Competing interests}

The authors disclose that they have no competing interests.

\section{Authors' contributions}

DB and HT carried out the experiments and performed the statistical analysis, JW and LH contributed to plasma sample collection and critical revision of the manuscript. CB provided endoglin constructs and contributed to critical revision of the manuscript. BW-S designed the study, wrote the manuscript, and contributed to data analysis. All authors read and approved the final manuscript.

\section{Acknowledgements}

This paper presents independent research that was supported by the National Institute for Health Research/Wellcome Trust Imperial Clinical Research Facility, at Imperial College Healthcare NHS Trust, London, UK. The views expressed are those of the authors and not necessarily those of the NHS, the NIHR or the Department of Health. This research was supported by a project grant (PG 11/13/28765) from the British Heart Foundation and by grants from Ministerio de Economia y Competitividad of Spain (SAF201343421-R to CB). CIBERER is an initiative of the Instituto de Salud Carlos III (ISCIII) of Spain supported by FEDER funds.

\section{Author details}

${ }^{1}$ Centre for Pharmacology and Therapeutics, Department of Medicine, Imperial College London, London, UK. ${ }^{2}$ National Pulmonary Hypertension Service, Imperial College Healthcare NHS Trust, London, UK. ${ }^{3}$ Centro de Investigaciones Biológicas, Consejo Superior de Investigaciones Científicas (CSIC), and Centro de Investigación Biomédica en Red de Enfermedades Raras (CIBERER), 28040 Madrid, Spain.

Received: 14 August 2015 Accepted: 11 January 2016

Published online: 19 January 2016

\section{References}

1. Lang IM, Pesavento R, Bonderman D, Yuan JX. Risk factors and basic mechanisms of chronic thromboembolic pulmonary hypertension: a current understanding. Eur Respir J. 2013;41(2):462-8. doi:10.1183/09031936.00049312.

2. Hoeper MM. Pharmacological therapy for patients with chronic thromboembolic pulmonary hypertension. Eur Respir Rev. 2015;24(136):272-82. doi:10.1183/16000617.00001015.

3. Alias S, Redwan B, Panzenbock A, Winter MP, Schubert U, Voswinckel R, et al. Defective angiogenesis delays thrombus resolution: a potential pathogenetic mechanism underlying chronic thromboembolic pulmonary hypertension. Arterioscler Thromb Vasc Biol. 2014;34(4):810-9. doi:10.1161/ATVBAHA.113.302991

4. Thaler J, Ay C, Pabinger I. Clinical significance of circulating microparticles for venous thromboembolism in cancer patients. Hamostaseologie. 2012;32(2):127-31. doi:10.5482/ha-1164.

5. Mittelbrunn M, Sanchez-Madrid F. Intercellular communication: diverse structures for exchange of genetic information. Nat Rev Mol Cell Biol. 2012;13(5):328-35. doi:10.1038/nrm3335.

6. Rautou PE, Vion AC, Amabile N, Chironi G, Simon A, Tedgui A, et al. Microparticles, vascular function, and atherothrombosis. Circ Res. 2011;109(5):593-606. doi:10.1161/CIRCRESAHA.110.233163.

7. Martinez MC, Tual-Chalot S, Leonetti D, Andriantsitohaina R. Microparticles: targets and tools in cardiovascular disease. Trends Pharmacol Sci. 2011;32(11):659-65. doi:10.1016/j.tips.2011.06.005.

8. van Dommelen SM, Vader P, Lakhal S, Kooijmans SA, van Solinge WW, Wood MJ, et al. Microvesicles and exosomes: opportunities for cell-derived membrane vesicles in drug delivery. J Control Release. 2012;161(2):635-44. doi:10.1016/j.jconrel.2011.11.021.

9. Tual-Chalot S, Guibert C, Muller B, Savineau JP, Andriantsitohaina R, Martinez MC. Circulating microparticles from pulmonary hypertensive rats induce endothelial dysfunction. Am J Respir Crit Care Med. 2010;182(2):261-8. doi:10.1164/rccm.200909-13470C

10. Bakouboula B, Morel O, Faure A, Zobairi F, Jesel L, Trinh A, et al. Procoagulant membrane microparticles correlate with the severity of pulmonary arterial hypertension. Am J Respir Crit Care Med. 2008;177(5): 536-43. doi:10.1164/rccm.200706-8400C.

11. Morel O, Jesel L, Freyssinet JM, Toti F. Cellular mechanisms underlying the formation of circulating microparticles. Arterioscler Thromb Vasc Biol. 2011;31(1):15-26. doi:10.1161/ATVBAHA.109.200956.

12. Morel O, Pereira B, Averous G, Faure A, Jesel L, Germain P, et al. Increased levels of procoagulant tissue factor-bearing microparticles within the occluded coronary artery of patients with ST-segment elevation myocardial infarction: role of endothelial damage and leukocyte activation. Atherosclerosis. 2009;204(2):636-41. doi:10.1016/j.atherosclerosis.2008.10.039.

13. Lopez-Novoa JM, Bernabeu C. The physiological role of endoglin in the cardiovascular system. Am J physiol Heart Circ Physiol. 2010;299(4):H959-74. doi:10.1152/ajpheart.01251.2009.

14. Upton PD, Morrell NW. The transforming growth factor-beta-bone morphogenetic protein type signalling pathway in pulmonary vascular homeostasis and disease. Exp Physiol. 2013;98(8):1262-6. doi:10.1113/expphysiol.2012.069104

15. Lebrin F, Goumans MJ, Jonker L, Carvalho RL, Valdimarsdottir G, Thorikay M, et al. Endoglin promotes endothelial cell proliferation and TGF-beta/ALK1 signal transduction. EMBO J. 2004;23(20):4018-28. doi:10.1038/sj.emboj.7600386.

16. Li C, Issa R, Kumar P, Hampson IN, Lopez-Novoa JM, Bernabeu C, et al. CD105 prevents apoptosis in hypoxic endothelial cells. J Cell Sci. 2003; 116(Pt 13):2677-85. doi:10.1242/jcs.00470.

17. Toporsian M, Jerkic M, Zhou YQ, Kabir MG, Yu LX, McIntyre BA, et al. Spontaneous adult-onset pulmonary arterial hypertension attributable to 
increased endothelial oxidative stress in a murine model of hereditary hemorrhagic telangiectasia. Arterioscler Thromb Vasc Biol. 2010;30(3):509-17. doi:10.1161/ATVBAHA.109.200121.

18. Oujo B, Perez-Barriocanal F, Bernabeu C, Lopez-Novoa JM. Membrane and soluble forms of endoglin in preeclampsia. Curr Mol Med. 2013;13(8):1345-57.

19. Gregory AL, Xu G, Sotov V, Letarte M. Review: the enigmatic role of endoglin in the placenta. Placenta. 2014;35(Suppl):S93-9. doi:10.1016/j. placenta.2013.10.020

20. Venkatesha S, Toporsian M, Lam C, Hanai J, Mammoto T, Kim YM, et al. Soluble endoglin contributes to the pathogenesis of preeclampsia. Nat Med. 2006;12(6):642-9. doi:10.1038/nm1429.

21. Guerrero-Esteo M, Sanchez-Elsner T, Letamendia A, Bernabeu C. Extracellular and cytoplasmic domains of endoglin interact with the transforming growth factor-beta receptors I and II. J Biol Chem. 2002;277(32):29197-209. doi:10.1074/jbc.M111991200.

22. Hristov M, Erl W, Linder S, Weber PC. Apoptotic bodies from endothelial cells enhance the number and initiate the differentiation of human endothelial progenitor cells in vitro. Blood. 2004;104(9):2761-6. doi:10.1182/blood-2003-10-3614.

23. Wojciak-Stothard B, Zhao L, Oliver E, Dubois O, Wu Y, Kardassis D, et al. Role of RhoB in the regulation of pulmonary endothelial and smooth muscle cell responses to hypoxia. Circ Res. 2012;110(11):1423-34. doi:10.1161/ CIRCRESAHA.112.264473.

24. Fiedler LR, Bachetti T, Leiper J, Zachary I, Chen L, Renne T, et al. The ADMA/ DDAH pathway regulates VEGF-mediated angiogenesis. Arterioscler Thromb Vasc Biol. 2009:29(12):2117-24. doi:10.1161/ATVBAHA.109.194035.

25. Liu Y, Jovanovic B, Pins M, Lee C, Bergan RC. Over expression of endoglin in human prostate cancer suppresses cell detachment, migration and invasion. Oncogene. 2002;21(54):8272-81. doi:10.1038/sj.onc.1206117.

26. Mause SF, Weber C. Microparticles: protagonists of a novel communication network for intercellular information exchange. Circ Res. 2010;107(9):1047-57. doi:10.1161/CIRCRESAHA.110.226456.

27. Quesenberry PJ, Aliotta JM. Cellular phenotype switching and microvesicles. Adv Drug Deliv Rev. 2010;62(12):1141-8. doi:10.1016/j.addr.2010.06.001.

28. Aliotta JM, Pereira M, Johnson KW, de Paz N, Dooner MS, Puente N, et al. Microvesicle entry into marrow cells mediates tissue-specific changes in mRNA by direct delivery of mRNA and induction of transcription. Exp Hematol. 2010:38(3):233-45. doi:10.1016/j.exphem.2010.01.002.

29. Hargett LA, Bauer NN. On the origin of microparticles: From "platelet dust" to mediators of intercellular communication. Pulm Circ. 2013;3(2):329-40. doi:10.4103/2045-8932.114760.

30. Martinez MC, Andriantsitohaina R. Microparticles in angiogenesis: therapeutic potential. Circ Res. 2011;109(1):110-9. doi:10.1161/CIRCRESAHA. 110.233049

31. Zernecke A, Bidzhekov K, Noels H, Shagdarsuren E, Gan L, Denecke B, et al Delivery of microRNA-126 by apoptotic bodies induces CXCL12-dependent vascular protection. Sci Signal. 2009;2(100):ra81. doi:10.1126/scisignal. 2000610.

32. Massague J, Cheifetz S, Boyd FT, Andres JL. TGF-beta receptors and TGFbeta binding proteoglycans: recent progress in identifying their functional properties. Ann N Y Acad Sci. 1990;593:59-72.

33. Derynck R, Feng XH. TGF-beta receptor signaling. Biochim Biophys Acta. 1997;1333(2):F105-50.

34. Vinals F, Pouyssegur J. Transforming growth factor beta1 (TGF-beta1) promotes endothelial cell survival during in vitro angiogenesis via an autocrine mechanism implicating TGF-alpha signaling. Mol Cell Biol. 2001;21(21):7218-30. doi:10.1128/MCB.21.21.7218-7230.2001.

35. Wang S, Aurora AB, Johnson BA, Qi X, McAnally J, Hill JA, et al. The endothelial-specific microRNA miR-126 governs vascular integrity and angiogenesis. Dev Cell. 2008;15(2):261-71. doi:10.1016/j.devcel.2008.07.002.

36. Finn NA, Searles CD. Intracellular and Extracellular miRNAs in Regulation of Angiogenesis Signaling. Curr Angiogenes. 2012;4(102):299-307.

37. Wilkins-Port CE, Higgins CE, Freytag J, Higgins SP, Carlson JA, Higgins PJ. PAI-1 is a Critical Upstream Regulator of the TGF-beta1/EGF-Induced Invasive Phenotype in Mutant p53 Human Cutaneous Squamous Cell Carcinoma. J Biomed Biotechnol. 2007;2007(2):85208. doi:10.1155/2007/85208.

38. Samarakoon R, Higgins CE, Higgins SP, Higgins PJ. TGF-beta1-Induced Expression of the Poor Prognosis SERPINE1/PAI-1 Gene Requires EGFR Signaling: A New Target for Anti-EGFR Therapy. J Oncol. 2009;2009:342391. doi:10.1155/2009/342391.
39. Beyer C, Pisetsky DS. The role of microparticles in the pathogenesis of rheumatic diseases. Nat Rev Rheumatol. 2010;6(1):21-9. doi:10.1038/ nrrheum.2009.229.

40. Tabibzadeh SS, Kong QF, Kapur S. Passive acquisition of leukocyte proteins is associated with changes in phosphorylation of cellular proteins and cell-cell adhesion properties. Am J Pathol. 1994;145(4):930-40.

41. Salanova B, Choi M, Rolle S, Wellner M, Luft FC, Kettritz R. Beta2-integrins and acquired glycoprotein IIb/IIla (GPIIb/IIla) receptors cooperate in NFkappaB activation of human neutrophils. J Biol Chem. 2007;282(38):27960-9. doi:10.1074/jbc.M704039200

42. Prokopi M, Pula G, Mayr U, Devue C, Gallagher J, Xiao Q, et al. Proteomic analysis reveals presence of platelet microparticles in endothelial progenitor cell cultures. Blood. 2009;114(3):723-32. doi:10.1182/blood-2009-02-205930.

43. Al-Nedawi K, Meehan B, Micallef J, Lhotak V, May L, Guha A, et al. Intercellular transfer of the oncogenic receptor EGFRvIII by microvesicles derived from tumour cells. Nat Cell Biol. 2008;10(5):619-24. doi:10.1038/ncb1725.

44. Obregon C, Rothen-Rutishauser B, Gitahi SK, Gehr P, Nicod LP. Exovesicles from human activated dendritic cells fuse with resting dendritic cells, allowing them to present alloantigens. Am J Pathol. 2006;169(6):2127-36. doi:10.2353/ajpath.2006.060453.

45. Mause SF, Ritzel E, Liehn EA, Hristov M, Bidzhekov K, Muller-Newen G, et al. Platelet microparticles enhance the vasoregenerative potential of angiogenic early outgrowth cells after vascular injury. Circulation. 2010; 122(5):495-506. doi:10.1161/CIRCULATIONAHA.109.909473.

46. Raposo G, Nijman HW, Stoorvogel W, Liejendekker R, Harding CV, Melief Cl, et al. B lymphocytes secrete antigen-presenting vesicles. J Exp Med. 1996;183(3):1161-72.

47. Johnstone RM, Adam M, Hammond JR, Orr L, Turbide C. Vesicle formation during reticulocyte maturation. Association of plasma membrane activities with released vesicles (exosomes). J Biol Chem. 1987;262(19):9412-20.

48. Blanchard N, Lankar D, Faure F, Regnault A, Dumont C, Raposo G, et al. TCR activation of human $T$ cells induces the production of exosomes bearing the TCR/CD3/zeta complex. J Immunol. 2002;168(7):3235-41.

49. Ardelean DS, Letarte M. Anti-angiogenic therapeutic strategies in hereditary hemorrhagic telangiectasia. Front Genet. 2015;6:35 doi:10.3389/fgene.2015.00035.

\section{Submit your next manuscript to BioMed Central and we will help you at every step:}

- We accept pre-submission inquiries

- Our selector tool helps you to find the most relevant journal

- We provide round the clock customer support

- Convenient online submission

- Thorough peer review

- Inclusion in PubMed and all major indexing services

- Maximum visibility for your research

Submit your manuscript at www.biomedcentral.com/submit
) Biomed Central 